\title{
DA PAISAGEM À ABSTRAÇÃo
}

Teresa Poester

\author{
"lembro-me que quando criança \\ eu via a manhã raiar sobre a cidade \\ hoje, por trás dos olhos, \\ vejo-me vendo..."
}

Do Livro do Desassossego, Fernando Pessoa

Minhas reflexões, de modo geral, sustentam a necessidade do desenho e da pintura como linguagens imprescindíveis à integração do corpo e da mente. Dentro das artes visuais, esta é, a meu ver, uma das especificidades das artes plásticas, num mundo que tende progressivamente a neutralizar o corpo como elemento ativo do conhecimento. Assim, numa perspectiva histórica, cabe observar-se o papel do motivo paisagem no processo de transformação da pintura que, abandonando as imposições da representação, prioriza o ato de pintar.

Sabemos que figuração e abstração são conceitos imprecisos que se fundem na prática pictórica. Entretanto, a idéia de abstração nos interessa como referência a um período em que a liberação do tema, antes primordial na avaliação do conteúdo pictórico, marca a autonomia do gesto na pintura ocidental.

Sem desconhecer outros caminhos possíveis no processo de desfiguração da imagem, através de motivos diversos, o objetivo deste texto é ressaltar especialmente certas características formais da paisagem que demonstram sua fragilidade mimética. A incidência do motivo a partir do século XIX não é acidental. Retomo essa idéia, já esboçada por mim anteriormente ${ }^{1}$, agora com novas reflexões que reafirmam a hipótese.

\section{Pintura e construção da paisagem}

O conceito de paisagem, no ocidente, é uma construção da Idade Moderna. A pintura como "uma janela para o mundo", com a inclusão da perspectiva e do quadro de cavalete, integra esta construção e acompanha o seu desenvolvimento. Os termos franceses paysage (pays como lugar de origem) provem do flamengo landschamp e é

\footnotetext{
${ }^{1}$ POESTER, Teresa. Entre Limites, uma pintura em trânsito. Dissertação de Mestrado. IA-UFRGS, Porto Alegre, 1995.
} 
utilizado pela primeira vez pelo poeta Jean Molinet (1493) para designar, de fato, uma pintura $^{2}$.

Não há como negar a influência da descrição pictórica na percepção da natureza. Charles Lapicque nos salienta como, através do olhar de diferentes pintores, o nosso entorno se torna impregnado dessa descrição: "A colina de Montmartre lembra Utrillo, o porto de Rouen, Marquet, os campos de Aix-en-Provence, Cézanne ${ }^{\prime 3}$.

Rosalind Krauss se serve da personagem Catherine, de Jane Austen, para comentar essa idéia contando a história da "gentil provinciana", que passeia com seus dois amigos eruditos que admiram a paisagem com olhos de pessoas acostumadas a desenhar e discutem "como utilizá-la num quadro". Catherine percebe que sua concepção provinciana do natural, "um céu claro é um belo dia", é completamente falsa e a paisagem vai sendo construída aos seus olhos através de seus companheiros mais cultos, "ele lhe falava de primeiro plano, de plano de fundo, de pontos de vista e de perspectiva, de iluminação e de sombra"t. E ainda, segundo a autora, comentando as observações do filho de William Gilpin, um dos principais teóricos do pitoresco, em carta à seu pai:

Que efeitos de melancolia e de esplendor. Eu não saberia descrever e não há mesmo necessidade pois basta você consultar os seus esboços para os ter diante dos olhos. Tenho um singular prazer em ver seus esboços tão plenamente confirmados pelas observações. Durante o passeio, para onde eu voltasse meus olhos, percebia seus "desenhos",

\section{Idéia de afastamento na construção da paisagem}

A idéia de afastamento tem sido também aceita e difundida por diferentes teóricos como condição necessária à construção da paisagem. Kant já observava que nossa erudição cultural denomina "sublime" aquilo que ao homem grosseiro aparece

\footnotetext{
${ }^{2}$ A primeira menção oficial do nome « paysage » figura no dicionário latim-frances de Robert Etienne (1549) .Citação de ROGERS, Alan, Court Traité du Paysage, Ed.Gallimard, Paris, 1997, pp.19/20.

${ }^{3}$ LAPICQUE, Charles, Essais sur l'espace, l'art et la destinée, Ed.Grasset., Paris, 1958, p. 135. Citação de ROGERS, op. cit., p. 21.

4 AUSTEN, Jane, Northanger Abbey (1818). Ttradução francesa de Josette Salesse-Lavergne, Paris, U.G.E., coll 10/18, 1983, pp. 99/100. Citação de KRAUSS, Rosalind, artigo: L'originalité de l'Avant Garde, em : L'originalité de l'Avant Garde et autres mytes modernistes, Ed. Macua, Paris, 1193, p.141.

${ }^{5}$ BARBIER, Carl Paul, citado em, Willian Gilpin, Oxford, The Carendon Press, 1963, p.111. Citação de KRAUSS, op. cit., p.141.
} 
como simplesmente "tenebroso"6. Alan Rogers salienta: "a paisagem é uma invenção do citadino que pressupõe o distanciamento e a cultura" ${ }^{\prime 7}$. Condições que podem ser discutidas já que o sentimento pragmático do agricultor não invalida necessariamente sua percepção estética. Mas a distância do olhar, seja ela de que ordem for, transforma a consciência da percepção da paisagem. A descoberta de novas culturas e das viagens contemplativas como fonte de prazer e interiorização marca o pensamento moderno.

O sentimento do exílio, tão exaltado pelos poetas românticos do Brasil, acentua a melancolia do lugar de origem como sonho e refúgio. Sentimento que os escravos na América, de norte a sul, tão significativamente expressaram, através da música, cantando o lamento da pátria perdida. Melancolia que, segundo Lyotard, esteve sempre ligada ao conceito de paisagem. Haverá paisagem, segundo o autor, cada vez que o espírito se deslocar de uma matéria sensível a uma outra conservando nesta a organização sensorial daquela ou, ao menos, sua lembrança ${ }^{8}$.

\section{Paisagem e abstração}

Ao observamos as obras de Turner, Monet, Cézanne, Kandinsky, Mondrian e Klee, entre outros, vemos um caminho que, partindo da contemplação da natureza como fonte de criação, perde gradualmente suas referências realistas. Se o motivo da paisagem não pode ser considerado como causa deste processo, sua incidência revela algumas características formais que merecem ser avaliadas.

A pintura paisagística no ocidente tem uma historia curta. Origina-se na Holanda durante o século XV, aparece de forma marcante no século XVII para tornar-se protagonista durante o século XIX. Com a laicidade do simbolismo medieval, os personagens da pintura renascentista inserem-se, gradativamente, num cenário realista dando lugar à paisagem. A construção gradual do gênero, protagonista da pintura romântica e da escola de Barbizon, prepara o caminho para impressionismo e para toda a transformação pictórica só século XX. Detenho-me aqui a estabelecer os aspectos gerais que sustentam a hipótese de acordo com minhas observações na História da Arte a partir do renascimento.

\footnotetext{
${ }^{6}$ ROGERS, Alan, op. cit., p.25.

${ }^{7}$ ROGERS, op. cit., p 27.

8 LYOTARD, Jean François, L'inhumain, causeries sur le temps, artigo publicado em : Revue de Sciences Humaines/ 1, 1988, número dedicado à « Ecrire le paysage » sob iniciativa de Jean-Marc Besse.
} 


\section{Subjetividade do motivo}

As noções preliminares que sustentam o estudo destas características compreendem as diferenças entre objeto e motivo, as relações entre tema e forma, assim como o próprio conceito de abstração na pintura.

O tema pode ser definido como motivo ou objeto. O termo "motivo" ${ }^{9}$, segundo Argan, um pretexto para o exercício da pintura, se aplica melhor à paisagem do que a idéia de "objeto" como modelo estático e previsível. Os pintores orientais, para quem o tema sempre desempenhou um papel secundário, contam com uma tradição antiqüíssima de pintura paisagística.

Se existem afinidades difíceis de dissociar entre tema e forma, é a relação entre os dois que determina as transformações e o desenvolvimento da pintura. Osborne, em Estética e Teoria da Arte, observa que o "bambu" oferece, para os pintores orientais, possibilidades mais sutis de expressão do que as cenas dramáticas ou anedóticas. O "bambu" é escolhido porque seu significado e suas características formais lhe conferem a neutralidade necessária à uma pintura não imitativa. Na arte ocidental, os "aspargos" de Manet constituem um exemplo dessa sobriedade e abrem caminho para a uma nova concepção pictórica. Neste sentido, o motivo, encerrando em si o conceito e a forma, não constitui um pretexto aleatório, mas uma escolha necessária ao exercício da pintura influindo sobre seu tratamento técnico e formal.

$\mathrm{O}$ motivo paisagem se presta plenamente à pintura oriental que registra um estado de espírito muito mais que uma representação do visível. Son $\mathrm{Di}$, um pintor chinês do século XI, revela:

Escolha um velho muro em ruínas, estenda sobre ele um pedaço de seda branca, observe-o, até que você possa ver, através da seda, seus relevos, seus níveis, suas fendas, os fixando em seu espírito e em seus olhos. Faça das proeminências suas montanhas, das partes mais baixas, seus lagos, das cavidades, seus vales (...) Você poderá então liberar o seu pincel segundo sua fantasia. E o resultado será uma coisa do céu e não do homem ${ }^{10}$.

Estas considerações antecipam os exercícios propostos por Leonardo da Vinci no "Tratado da Pintura".

\footnotetext{
${ }^{9}$ ARGAN, Giulio Carlo, Arte Moderna, Ed. Companhia das Letras, São Paulo, 1992, p.60.

${ }^{10}$ Citação de Hubert DAMISCH, Théorie du Nuage, Éd. du Seuil, Paris, 1972 , p. 52.
} 
Da Vinci, explorando a imaginação pictórica a partir de manchas encontradas nos muros ao acaso, já recomendava cuidado com a utilização da paisagem que, por sua consistência frágil, se tornava um motivo especialmente perigoso ${ }^{11}$.

Alexander Cozens (1717-86) retoma as considerações de Leonardo nos seus "Fundamentos sobre a pintura de paisagem" e pinta a partir de manchas aleatórias afirmando que inventar uma paisagem não é imitar a natureza mas utilizar seus princípios para a criar artificialmente. Em outras palavras, é a imaginação e não a observação, o fundamento da pintura de paisagens.

Embora a observação direta da natureza fosse utilizada freqüentemente como estudo já durante a renascença, a pintura concluída en plein air começa em fins do século XVIII e se intensifica como prática durante o impressionismo. Chateaubriand já recomendava aos pintores que trabalhassem ao ar livre e que procurassem estudar a botânica, que compara à anatomia, necessária ao conhecimento da paisagem. Anatomia que nos fala dos ossos e músculos de um motivo metaforicamente comparado à pele do mundo.

Mas os aspectos fidedignos do motivo não parecem prevalecer sobre as fantasias oníricas que se espelham na natureza com suas intempéries, suas nuvens, seus movimentos de luzes e ventos. Gombrich insiste especialmente nesta subjetividade do motivo:

Não se poderá argumentar então que, quando a maneira clássica da pintura morreu de morte natural no século de XVIII, é esta nova função da arte que traz a pintura de paisagens para o primeiro plano e obriga o artista a intensificar a busca de suas próprias verdades?

É o romantismo, entretanto, no século XIX, que prioriza a imaginação no processo de criação individual e que coloca a paisagem como motivo central da pintura.

\section{Paisagem como cenário de fundo}

A paisagem, anteriormente utilizada como cenário de fundo para situar os personagens na cena principal, proporciona uma liberdade maior ao pintor que freqüentemente negligencia o seu acabamento em contraste com a elaboração do primeiro plano tratado meticulosamente. Goldemberg nos convida a observar certas

\footnotetext{
${ }^{11}$ DA VINCI, Leonardo, Le traité de la peinture, Ed.Chastel, Berger Levault, Paris, 1987.
} 
telas de Boticcelli para ilustrar esta liberação de precisão ${ }^{12}$. Gainsborough e Goya antecipam o romantismo no tratamento diferenciado que o papel secundário do motivo permite.

\section{Ausência da figura humana}

É a partir do século XVII, quando o homem deixa de pertencer à escada de relações no espaço do quadro e não se reconhece mais como objeto de representação, que a paisagem marca uma inversão de papéis na pintura. A ausência da figura humana libera a hierarquia imposta às cenas narrativas e aos retratos suprimindo o foco visual do quadro. Cria-se assim um ambiente neutro onde os valores não obedecem mais a uma ordem pré-estabelecida.

Pode-se dizer que o dado subjetivo, a paisagem, se apresenta ao artista como motivo quando se presta a ser experimentado como um espaço unitário onde nenhuma graduação é possível mas somente uma perfeita igualdade entre todos os valores ${ }^{13}$.

Não existe mais o contorno entre figura e fundo determinado pelo retrato ou pela natureza morta. O quadro se reveste de texturas visuais que se interpenetram.

\section{Paisagem e perspectiva}

Uma vez alterada a relação figura-fundo, a paisagem determina campos de visão que se combinam em benefício da unidade do todo. Os planos, marcados pela utilização da perspectiva linear, são substituídos por relações mais sutis que determinam outras profundidades de campo, como descreve Cozens: "As sensações visuais se apresentam como manchas mais claras, mais escuras, coloridas de maneira variada, e não seguindo um esquema geométrico como o da perspectiva clássica"14. Perspectiva que surgiu com a arquitetura urbana não encontrando as mesmas referências formais na representação da natureza.

Em suas considerações sobre a perspectiva aérea, Leonardo de Vinci observava que a noção de distância é representada por meio de nuanças de cor mais ou menos

\footnotetext{
${ }^{12}$ GOLDBERG, Itzhak, no artigo: Défigurations du paysage em: CHENET, Françoise. Le paysage et ses Grilles. Actes du colloque de Cerisy-la-Salle. Ed. L'Harmattan, Paris, 1996, p. 230.

${ }^{13}$ ARGAN, 1993, op. cit., p. 60.

${ }^{14}$ ARGAN, 1993, op. cit., p. 18.
} 
saturadas. $\mathrm{O}$ ar, conforme sua concepção, constituído de graxa, é azulado. Quanto mais longe se encontrar uma montanha, proporcionalmente maior será a quantidade de azul entre ela e o observador. Seus exemplos são facilmente aplicáveis às vistas naturais. Assim, a perspectiva aérea, como procedimento tipicamente pictórico, se aplica mais especificamente à paisagem do que a perspectiva linear, como recurso do desenho.

Turner, num período em que o tema não poderia ser dispensado, cria uma espécie de "perspectiva meteorológica"15 que ilustra o caráter subjetivo do motivo e antecipa toda a transformação da pintura preparada pelo século XIX.

\section{Movimentos de luz}

O tratamento cromático da paisagem, se compondo de uma quantidade infinita de tonalidades, torna ainda mais difícil a distinção nítida das formas. Gombrich ressalta, na instabilidade do modelo, os movimentos de luz e sombra que dificultaram a representação realista:

Se o pintor de retrato ou de natureza morta tem a intenção de copiar as zonas de cor desses motivos, ele não pode permitir que um raio de luz venha transformar o processo. $\mathrm{O}$ pintor de paisagem tem ainda menos possibilidades para uma imitação literal $^{16}$.

$\mathrm{Na}$ paisagem, as formas freqüentemente são enfumaçadas como nuvens e os elementos se alternam sem cessar. O impressionismo explora seus movimentos, reflexos e deformações. Uma pintura que priorizava a luz e pretendia captar o momento efêmero não poderia ter escolhido motivo mais apropriado.

\section{Abolição do motivo}

Mesmo que o motivo da paisagem inaugure uma ruptura com o objeto como modelo de representação ela representa ainda um espaço real situado entre o céu e a terra. Entretanto as relações entre os elementos desse espaço mudam e se centram nos valores dispersos da composição do quadro que se torna o grande desafio para o pintor de paisagem.

\footnotetext{
${ }^{15}$ GOLDBERG, op. cit., p. 228.

${ }^{16}$ GOMBRICH, Op. cit., p. 31.
} 
O pintor, precisando se distanciar do motivo, não é atraído pelas figuras separadamente mas pelas relações entre as partes que traduzem a sensação desejada. A visão do todo se impõe assim, em detrimento dos detalhes, tornando dispensável a forma de uma folha mas imprescindível a textura que permite a idéia de conjunto dos diferentes arbustos e plantas. A noção de espaço unitário e amplo, limitado segundo a determinação do olhar do pintor, faz com que esse olhar ganhe autonomia, passando a recortar o real segundo seus próprios critérios. Neste sentido o que se pretende é que a paisagem seja encarada como um motivo que propicia a abolição do motivo.

Os contornos se apagam e as formas se fusionam facilitando a emergência das manchas de cor. Uma vez alterada a profundidade de campo, os planos marcados pela utilização da perspectiva linear, segundo Goldberg, são substituídos por zonas de percepção determinadas por novos recursos de tratamento ${ }^{17}$. Quando a profundidade de campo é reduzida, a pintura se torna mais plana.

É a apropriação dessa superfície física do quadro como objeto bidimensional a característica primordial da pintura no século XX.

\section{Abstração}

Pode-se perceber a incidência da paisagem tanto no processo de abstração informal como geométrica. De acordo com Goldberg, podemos ver aqui duas tendências: uma que insiste na dissolução provocada pelo motivo, inaugurada pelos impressionistas, e outra que se centra na construção do quadro, iniciada por Cézanne ${ }^{18}$.

Por um lado, as paisagens impressionista e fauvista propiciam a separação de linhas e manchas já explorando procedimentos autônomos da pintura. Estabelece-se a busca dos valores plásticos de expressão individual em direção ao "princípio da necessidade interior" que sustenta a obra de Kandinsky. Por outro lado, a concepção paisagística de Poussin é retomada por Cézanne que reafirma o valor da forma preparando o caminho para o Cubismo e para o Concretismo de Mondrian. Cézanne, segundo Argan, foi muito além do caráter francês do impressionismo como flagrante do momento instantâneo e compreendeu a importância da estrutura ortogonal na composição da paisagem.

\footnotetext{
${ }^{17}$ GOLDBERG, op. cit., p. 229.

${ }^{18}$ GOLDBERG, op. cit.
} 
Se tudo cresce verticalmente - árvores, plantas e animais - as linhas de terra conferem horizontalidade ao motivo. A estrutura paisagística é composta desse feixe de ortogonais, síntese da composição que, segundo a tradição oriental, estabelece o princípio fundamental que rege todas as coisas. Shitao escreve a esse respeito: "A dispersão ou o agrupamento, a profundidade e a distância, constituem a organização esquemática; verticais e horizontais; depressões e relevos, constituem o ritmo" ${ }^{\text {"19. }}$.

Estabelecer o ritmo do quadro através de novos parâmetros tem sido uma característica da abstração. A tradição da paisagem oriental tão fortemente ligada à caligrafia, com seus traços e pinceladas rápidas, parece capturar a alma das coisas, o ritmo da natureza, o espírito que habita cada uma de suas partes.

O ritmo integra as noções de tempo e espaço, construção pictórica e musical. Kansinsky e Paul Klee, músicos e pintores, traduzem o tempo como freqüência e movimento do gesto no espaço da tela. O ritmo torna-se a pulsão que anima o quadro.

\section{Epílogo}

A percepção do homem do século XIX estava suficientemente preparada para aceitar as novas descobertas científicas que transformariam definitivamente o olhar. Não podemos estabelecer limites precisos entre o que pode ser visto e o que pode ser imaginado. O telescópio, o microscópio, a velocidade, a fotografia e o cinema, mostram novas possibilidades de percepção e de representação do visível que foram incorporadas ao homem do século XX. A fotografia não somente registra o visível mas torna possível uma nova compreensão do real.

Assim, numa perspectiva histórica da pintura, cabe observar-se o papel do motivo paisagem no processo de transformação da linguagem que, abandonando as imposição da representação, prioriza o ato de pintar.

\footnotetext{
${ }^{19}$ SHITAO. Propos sur la peinture. Paris: Ed. Hermann, 1984. pp. 67-68.
} 


\section{REFERÊNCIAS}

POESTER, Teresa. Entre Limites, uma pintura em trânsito. Dissertação de MestradoIA- UFRGS, Porto Alegre, 1995.

ROGERS, Alan. Court Traité du Paysage. Ed.Gallimard, Paris, 1997, p.19/20.

LAPICQUE, Charles. Essais sur l'espace, l'art et la destine. Ed.Grasset, Paris, 1958, p.

135. Citação de ROGERS, op. cit., p21.

AUSTEN, Jane. Northanger Abbey (1818). Ttradução francesa de Josette SalesseLavergne, Paris, U.G.E., coll 10/18, 1983, p. 99/100. Citação de KRAUSS, Rosalind, artigo: L'originalité de l'Avant Garde, em : L'originalité de l'Avant Garde et autres mytes modernistes, Ed. Macua, Paris, 1193, p.141.

BARBIER, Carl Paul. citado em, Willian Giltpin Oxford, The Carendon Press, 1963, p.111. Citação de KRAUSS, op. cit., p.141.

LYOTARD, Jean François. L'inhumain, causeries sur le temps. artigo publicado em Revue de Sciences Humaines/ 1, 1988, número dedicado à "Ecrire le paysage" sob iniciativa de Jean- Marc Besse.

ARGAN, Giulio Carlo. Arte Moderna. Ed. Companhia das Letras, São Paulo, 1992.

DA VINCI, Leonardo. Le traité de la peinture. Ed.Chastel, Berger Levault, Paris, 1987. GOMBRICH, E. H. Arte e Ilusão. Rio de Janeiro, Martin Fontes, 1959, p.155.

GOLDEMBER, Itzak. no artigo: Défigurations du paysage em: CHENET, Françoise. Le paysage et ses Grilles. Actes du colloque de Cerisy-la-Salle. Ed. L'Harmattan, Paris, 1996, p.230.

SHITAO. Propos sur la peinture. Paris, Ed. Hermann, 1984, p.67-68.

\section{CITAÇÕES EM FRANCÊS}

3- LAPICQUE, Charles. Essais sur l'espace, l'art et la destinée. Ed.Grasset, Paris, 1958, p.135.

Citação de ROGERS, op. cit., p.21

"La butte de Montmartre ressemble à Utrillo, le port de Rouen à Marquet, la campagne de Aix-en-Provence à Cézane".

4 - AUSTEN, Jane, Northanger Abbey (1818). Ttradução francesa de Josette Salesse-

Lavergne, Paris, U.G.E., coll 10/18, 1983, pp. 99/100. Citação de KRAUSS, Rosalind, artigo: L'originalité de l'Avant Garde, em : L'originalité de l'Avant Garde et autres mytes modernistes, Ed. Macua, Paris, 1193, p.141

"Il lui parla de premiers plans, d'arrière-plans, de second plans, de points de vue et de perspectives, d'éclairages et d'ombres".

5 - BARBIER, Carl Paul, citado em, Willian Giltpin, Oxford, The Carendon Press, 1963, p.111. Citação de KRAUSS, op. cit., p.141

"Alors, quels effets de mélancolie et splendeur. Je ne peux pas les décrire - et je n'en ai pas besoin, car il vous suffit de regarder votre propre resserve d'esquisses pour les avoir. J'ai eu néanmoins un singulier plaisir à voir votre système d'effets si pleinement confirmé par les observations faites durant dette journée: où que je me tournasse mes yeux, j'apercevais un de ses dessins".

- ROGERS, Alan, op. cit., p. 25

" Ce que, préparés par la culture, nous nommons sublime, apparaîtra à l'homme grossier sans éducation morale, simplement comme effrayant".

7 - ROGERS, op. cit., p. 27

" La perception d'un paysage, cette invention de citadins, suppose à la fois du recul et 
de l culture".

8 - LYOTARD, Jean François. L'inhumain, causeries sur le temps, artigo publicado em: Revue de Sciences Humaines/1, 1988, número dedicado à « Ecrire le paysage »sob iniciativa de Jean-Marc Besse.

"Il aura paysage chaque fois que l'esprit se déportera d'une matière sensible dans une autre en conservant de celle-ci l'organisation sensorielle convenable pour celle là, ou du moins son souvenir".

10 - Citação de Hubert DAMISCH, Théorie du Nuage, Éd. du Seuil, Paris, 1972 , p. 52 Son Di, pintor chinês :

"Choisissez un vieux mur en ruine, étendez sur lui un morceau de soie blanche. Alors, soir et matin, regardez le jusqu'à ce qu'à la fin vous puissiez voir la ruine à travers la soie, ses bosses, ses niveaux, ses zigzags, ses fentes, les fixant dans votre esprit et dans vos yeux. Faites des proéminences vos montagnes, des parties les plus baisses vos eaux, des creux vos ravins". (...) Vous pourrez alors jouer de votre pinceau selon votre fantaisie. Et le résultat sera une chose du ciel et non de l'homme".

20 - SHITAO. Propos sur la peinture. Paris, Ed. Hermann, 1984, pp. 67, 68

"La dispersion ou le groupement, la profondeur et la distance constituent l'organisation schématique; verticales et horizontales, creux et reliefs constituent le rythme; ombres et lumière, épaisseur et fluidité constituent la tension spirituelle”.

As traduções do francês foram efetuadas pela autora Revista Critica de Ciências Sociais e Humanas 22/23

ULBRA, Porto Alegre, 2003 